\title{
Individual-level data sources used for secondary analysis
}

Afrobarometer (1999-2009)

American National Election Studies (1958-2012)

AmericasBarometer (2008, 2010)

Arab Barometer (2006-2011)

Asian Barometer Survey (2001-2011)

Belgian Political Panel Survey (2006-2011)

Canadian Election Studies (1965-2011)

Candidate Country Eurobarometer (2001-2004)

Eurobarometer, Standard (2001-2013)

European Social Survey (2002-2012)

General Social Survey (1966-2014)

Global Barometer (2007)

Latinobarometer (1996-2011)

Life in Transition Survey 2 (2011)

National Annenberg Election Survey (2000)

National Survey of Americans' Views on Taxes (2003)

World Values Survey / European Values Study (1981-2014) 